\title{
Using statistical analysis to mitigate risk in environmental programs
}

\author{
K. Tiedemann \\ BC Hydro and Simon Fraser University, Canada
}

\begin{abstract}
Greenhouse gas emissions and local pollutants due to fossil fueled power generation are increasingly being recognized as major threats to the environment. A number of programs have been implemented to reduce emissions in developing countries, but less emphasis has been placed on rigorous evaluation of these programs to understand whether or not they are meeting their objectives and if the estimates of program impacts are reliable. The Efficient Lighting Initiative (ELI) is a seven-country program implemented by the International Finance Corporation in Argentina, the Czech Republic, Hungary, Latvia, Peru, the Philippines and South Africa. The objective of the overall ELI program is to reduce greenhouse gas emissions by promoting the use of modern and high-quality lighting products to transform domestic lighting markets. This study uses statistical modeling to evaluate the impact of the ELI program on: (1) sales of efficient lamps; (2) energy use; and (3) carbon dioxide, sulphur dioxide and nitrous oxide emissions.

Keywords: energy conservation, program evaluation, regression analysis, green house gas emissions, environmental risk.
\end{abstract}

\section{Introduction}

Greenhouse gas emissions and local pollutants due to fossil fueled power generation are increasingly being recognized as major threats to the environment. Carbon dioxide is the key greenhouse gas and has been implicated in global warming, which potentially threatens the health and livelihood of millions of people (United Nations Environmental Programme [1]). A number of common pollutants, including sulphur dioxide and nitrous oxides, harm human health and have been categorized as criteria pollutants by the World Health Organization [2]. Electric power generation is a major source of carbon dioxide, sulphur 
dioxide and nitrous oxide emissions as well as other pollutants (United Nations Framework on Convention on Climate Change [3]).

The development community is spending considerable amounts of money on encouraging energy efficiency on developing countries, with a view to reducing emissions and their impacts, but the development of appropriate evaluation techniques has not kept pace with these expenditures. There is thus a significant risk that some programs are not achieving their planned objectives, and that funds may be spent on energy conservation activities that might well have occurred even without the planning and implementation of these programs (Hobbs et al. [4]).

This paper uses statistical methods to examine the impact of the International Efficient Lighting Initiative (ELI) program on sales of energy efficient lighting and on emissions in four developing countries. Several previous studies have used similar econometric methods to analyze the impact of market transformation programs in developed countries. Duke and Kammen [5] found that accounting for feedback between the demand response and production response for electronic ballasts increases the consumer benefit cost ratio. Horowitz [6] found that coordinated national electronic ballast programs were more cost effective than local efforts. Horowitz and Haeri [7] found that the cost of energy efficiency investments was fully capitalized in housing prices and that purchasing an energy efficient house was cost effective. Jaffe and Stavins [8] found that insulation levels in new residential housing appropriately reflect energy prices.

\section{Background}

The Efficient Lighting Initiative (ELI) is a seven-country program implemented by the International Finance Corporation in Argentina, the Czech Republic, Hungary, Latvia, Peru, the Philippines and South Africa. The main objective of the ELI program is to reduce greenhouse gas emissions by promoting the use of modern and high-quality lighting products to transform domestic lighting markets. The program also has impacts on major pollutants including sulphur dioxide and nitrous oxide.

The market for lighting products in the four developing ELI countries reflects the economic and social dualism characteristic of these countries. Lower income residential customers typically purchase their lamps at smaller grocery and general-purpose stores. These stores frequently carry only $25 \mathrm{~W}$ to $100 \mathrm{~W}$ Type A lamps. Middle income and upper income residential customers have access to wide variety of stores including department stores, hypermarkets, chain stores, hardware stores and lighting stores. These stores carry a wider range of lighting products including a variety of GLS lamps, a range of CFLs, energy efficient T5 and $\mathrm{T} 8$ tubes and T12 tubes. Business customers, especially those in urban areas, have a wider range of options. These include building supply stores, larger hardware stores and full service lighting stores, which often carry a full range of lighting products. Domestic manufacturing of lighting products is limited in the ELI countries, with most efficient products being imported. Given their small 
domestic markets, all developing ELI countries have problems achieving economies of scale.

Each ELI program initiative falls into one of five methods of market intervention: public awareness and education, utility programs, transaction support, market aggregation, and financial incentives. Through these market interventions, ELI sought to achieve its goals by: (1) providing consumers with reliable information with which they can make educated purchasing decisions and which will allow high-quality lighting products to compete fairly; (2) strengthening the manufacturing, service, distribution and retail capacity of the local efficient lighting market; and (3) supporting commercial financial mechanisms that will allow more consumers to purchase energy-efficient lighting products.

\section{Model and data}

It is convenient to view a single lamp or tube market (such as the market for ELI approved, high quality CFLs) in isolation and abstract from linkages to other markets or general equilibrium effects. Consider the following simple fourequation model where (1) is the demand curve, (2) is the stochastic process for the path of income over time, (3) is the supply curve, and (4) is the stochastic process for import prices over time, and the error terms have been suppressed for convenience.

$$
\begin{aligned}
& \text { quantity }_{t}=a+b^{*} \text { price }_{t}+c^{*} \text { income }_{t}+d^{*} \text { dummy }_{t} \\
& \text { income }_{t}=e+f^{*} \text { time }_{t} \\
& \text { price }_{t}=g+h * \text { import price }_{t}+i * \text { dummy }_{t} \\
& \text { import price }_{t}=j+k^{*} \text { time }_{t}
\end{aligned}
$$

In these equations, quantity $y_{t}$ is domestic market demand for the lighting appliance at time $t$, price $t_{t}$ is unit price of the lighting appliance at time $t$, income $e_{t}$ is total domestic income at time $t$, time $_{t}$ is the year $t$, import price $t_{t}$ is the per unit at time $t$, and dummy is a shift variable that takes the variable " 0 " in the pre-ELI program period and the value " 1 " in the ELI program period.

Equation (1) represents the demand curve for a lighting appliance in year t. It says that market demand for the lighting appliance is a linear function of product price, total domestic income and a preference variable, which represents a shift in consumer demand towards the product of interest. This demand shift could be driven by ELI program advertising and promotional activities or by other factors, but in any event reflects consumer views of relative value of the product compared to other products. Equation (2) represents the path of income over time. It says that the path of income can be adequately represented by a (stochastic) linear trend. Over the relatively short period of data available, this is a reasonable assumption.

Equation (3) represents the supply curve for a lighting appliance in year t. It says that that lighting appliance price is a linear function of the import price and a supply shift variable. The supply shift variable represents a shift in domestic 
supply towards higher efficiency appliances (or away from lower efficiency appliances) as a result of changes in producer preferences, perhaps as a result of ELI marketing initiatives, or the effect of a subsidy.

Equation (4) is the import price that is constant over a given year but decreases over time due to experience curve effects and increased competition due to market transformation.

Substituting for income in (1) and substituting for import price in (3) yields a simple structural equation model with two equations in two variables, quantity and price. Solving this model for price and for quantity yields in turn the reduced form of this structural model as follows:

$$
\begin{gathered}
\text { quantity }_{t}=\alpha+\beta^{*} \text { time }+\chi^{*} \text { dummy }_{t} \\
\text { price }_{t}=\delta+\phi^{*} \text { time }+\gamma^{*} \text { dummy }_{t}
\end{gathered}
$$

Equation (5) represents the reduced form equation for quantity. Note that it has been rearranged so that quantity depends on a constant plus a time trend plus a term that represents ELI program impacts.

Equation (6) represents the reduced form equation for price, which in this model is the same as the supply equation. Note that it has been rearranged so that price depends on a constant plus a time trend plus a term that represents ELI program impacts. We provide estimates of equations (5) and (6) in the next section.

A number of data sources were used to inform this analysis. At the time of ELI program launch, all participating countries were to complete the performance data matrix that had been developed by the Evaluation Team, covering in particular data for 1999 through 2001. This data included, in particular, manufacturers' reported sales and price data for lighting products. During the summer of 2002 a baseline survey was conducted in each of the ELI countries. This covered actual sales in 2001 as well as projected sales for 2002 and 2003. In some cases, additional national surveys were conducted for 2002 and 2003 and this was supplemented by import data.

\section{Product sales and prices}

To estimate the impact of ELI on sales of a particular lighting product, we use a simple econometric model, where sales in thousands of units are a function of a time trend and a dummy variable for the ELI program. For Argentina only, the model includes an additional dummy variable to adjust for the effects of the 2001 economic crisis. The two-year ELI program impact for each product in each country, in thousands of units, then equals the ELI regression coefficient multiplied by two. The period covered by the analysis is 1997 through 2002.

For each country, the coefficients for each variable are given in the appropriate column with the t-statistic below in parentheses. The log-likelihood statistic (a measure of goodness of fit) and the Durbin-Watson statistic (a measure of auto-correlation) are shown. It should be noted that since we are using time-series data, we initially estimated the equations using both ordinary least squares (OLS) and maximum likelihood (ML) assuming first-order autocorrelation in the residuals. Auto-correlation refers to the possibility that the 
error terms in the regression are correlated over time. The possible presence of auto-correlation is tested using the Durbin-Watson statistic.

Table 1 shows that the estimated increase per year of CFL sales due to the ELI program is 963,000 units in Argentina, 2,883,000 units in Peru, 1,381,000 units in Philippines and 1,890,000 units in South Africa. In this and the following tables, these numbers are doubled to produce the program impact over two years.

Table 2 shows that the estimated change per year of GLS sales due to the ELI program is a reduction of 18,626,000 units in Argentina, 2,883,000 units in Peru, 1,381,000 units in Philippines and 1,890,000 units in South Africa.

Table 3 shows that the estimated increase per year of T5-T8 fluorescent tubes sales due to the ELI program is 151,000 units in Argentina, 209,000 units in Peru, 177,000 units in Philippines and 1,297,000 units in South Africa. In addition, the estimated increase per year of sodium vapor lamps in Peru is 148,000 units.

Table 4 shows that the estimated increase per year of T12 fluorescent tubes sales due to the ELI program is 151,000 units in Argentina, 209,000 units in Peru, 177,000 units in Philippines and 1,297,000 units in South Africa. In addition, the estimated increase per year of sodium vapor lamps in Peru is 148,000 units.

Table 1: $\quad$ Impact of ELI on CFL sales (thousands).

\begin{tabular}{|l|l|l|l|l|}
\hline & Argentina & Peru & Philippines & South Africa \\
\hline Constant & 485 & -299 & 2,286 & 1,071 \\
& $(0.35)$ & $(-0.75)$ & $(4.67)$ & $(5.72)$ \\
\hline Year & 998 & 237 & -400 & 304 \\
& $(2.27)$ & $(1.94)$ & $(2.18)$ & $(4.35)$ \\
\hline ELI & 963 & 2,883 & 1,381 & 1,890 \\
& $(0.55)$ & $(5.25)$ & $(2.07)$ & $(7.62)$ \\
\hline Devaluation & $-5,687$ & - & - & - \\
& $(-4.65)$ & & & \\
\hline Log-likelihood & -56.6 & -52.9 & -43.6 & -39.2 \\
\hline DW & 1.51 & 3.39 & 2.83 & 3.61 \\
& $(0.25)$ & $(-0.69)$ & $(-0.42)$ & $(-0.81)$ \\
\hline
\end{tabular}

Note: T-statistics for coefficients are shown in parentheses. DW is the Durbin-Watson statistic.

Table 2: $\quad$ Impact of ELI on GLS sales (thousands).

\begin{tabular}{|l|l|l|l|l|}
\hline & Argentina & Peru & Philippines & South Africa \\
\hline Constant & 161,129 & 20,096 & 23,836 & 42,262 \\
& $(25.7)$ & $(26.2)$ & $(17.1)$ & $(6.88)$ \\
\hline Year & -87 & -535 & -79 & 5,229 \\
& $(-0.04)$ & $(-2.27)$ & $(-0.15)$ & $(2.27)$ \\
\hline ELI & $-18,626$ & -689 & -576 & $-14,928$ \\
& $(-1.50)$ & $(-0.65)$ & $(-0.31)$ & $(-1.78)$ \\
\hline Devaluation & 12,740 & - & - & - \\
& $(0.85)$ & & & \\
\hline Log-likelihood & -69.5 & -55.0 & -51.2 & -58.7 \\
\hline DW & 3.09 & 2.44 & 3.27 & 2.62 \\
& $(-0.54)$ & $(-0.22)$ & $(-0.64)$ & $(-0.31)$ \\
\hline
\end{tabular}

Note: T-statistics for coefficients are shown in parentheses. DW is the Durbin-Watson statistic. 
Table 3: $\quad$ Impact of ELI on T5-T8 and sodium vapor sales (thousands).

\begin{tabular}{|l|l|l|l|l|l|}
\hline & Argentina & Peru & Philippines & Peru & South Africa \\
\hline & T5-T8 & T5-T8 & T5-T8 & Sodium & T5-T8 \\
\hline Constant & 7,026 & 115 & 2,453 & 262 & 5,771 \\
& $(15.77)$ & $(1.76)$ & $(84.2)$ & $(5.37)$ & $(18.69)$ \\
\hline Year & 140 & 81 & 34 & -15 & -211 \\
& $(0.95)$ & $(4.02)$ & $(3.14)$ & $(1.01)$ & $(1.82)$ \\
\hline ELI & 151 & 209 & 177 & 148 & 1,297 \\
& $(1.22)$ & $(2.31)$ & $(4.58)$ & $(2.20)$ & $(3.13)$ \\
\hline Devaluation & -389 & - & - & - & - \\
& $(-0.91)$ & & & & -41.4 \\
\hline Log- & -48.9 & -39.8 & -27.8 & -35.7 & \\
likelihood & & & & & 3.09 \\
\hline DW & 1.80 & 3.01 & 2.84 & 1.89 & $(0.06)$ \\
& $(0.10)$ & $(-050)$ & $(-0.42)$ & $(-0.55)$ \\
\hline
\end{tabular}

Table 4: $\quad$ Impact of ELI on T12 and mercury vapor sales (thousands).

\begin{tabular}{|l|l|l|l|l|l|}
\hline & Argentina & Peru & Philippines & Peru & South Africa \\
\hline & T12 & T12 & T12 & Mercury & T12 \\
\hline Constant & 11,271 & 2,777 & 11,478 & 63 & 5.191 \\
& $(50.1)$ & $(6.7)$ & $(133.6)$ & $(3.4)$ & $(14.9)$ \\
\hline Year & -129 & 668 & 263 & -0.51 & -193 \\
& $(-1.52)$ & $(5.25)$ & $(8.22)$ & $(-0.09)$ & $(-1.48)$ \\
\hline ELI & -425 & -136 & -551 & 31 & 591 \\
& $(-0.97)$ & $(-0.24)$ & $(-4.82)$ & $(1.25)$ & $(1.25)$ \\
\hline Devaluation & -849 & - & - & - & - \\
& $(-1.65)$ & & & & \\
\hline Log- & -45.9 & -51.1 & -34.2 & -28.2 & -41.9 \\
likelihood & & & & & \\
\hline DW & 3.51 & 2.71 & 3.16 & 1.44 & 3.04 \\
& $(-0.76)$ & $(-0.36)$ & $(-0.58)$ & $(0.28)$ & $(-0.52)$ \\
\hline
\end{tabular}

Table 5: $\quad$ Impact of ELI on CFL lamp prices.

\begin{tabular}{|l|l|l|l|l|}
\hline & Argentina & Peru & Philippines & South Africa \\
\hline Currency & peso & new sol & peso & rand \\
\hline Constant & 29.1 & 27.6 & 276 & 3.55 \\
& $(122.0)$ & $(116.0)$ & $(125)$ & $(148.3)$ \\
\hline Year & -1.82 & -1.72 & -1.66 & -0.074 \\
& $(-20.3)$ & $(-19.2)$ & $(-2.02)$ & $(-8.32)$ \\
\hline ELI & -0.67 & -0.47 & -15.2 & -0.14 \\
& $(-1.22)$ & $(-1.16)$ & $(-5.16)$ & $(-4.42)$ \\
\hline Devaluation & -0.67 & - & - & - \\
& $(-2.08)$ & & & \\
\hline Log-likelihood & -1.93 & -1.90 & -12.2 & -15.2 \\
\hline DW & 2.58 & 2.00 & 3.16 & 3.50 \\
& $(-0.29)$ & $(-0.00)$ & $(-0.58)$ & $(-0.75)$ \\
\hline
\end{tabular}

Table 5 shows the impact of ELI on CFL prices. Price series for other types of lamps were not available. The estimated impact of ELI is a reduction of CFL prices of 0.67 peso per year in Argentina, 0.47 new sol per year in Peru, 15.2 peso per year in the Philippines and 0.14 rand per year in South Africa. 


\section{Energy savings and emissions reductions}

Energy savings were estimated for CFLs, T8 tubes and high pressure sodium lamps for those countries where the data was adequate to allow econometric estimates of ELI program impacts. Energy savings are defined as change in load multiplied by average annual hours multiplied by ELI program impact on sales. For screw-type lamps, it is assumed that an 18 watt CFL replaces, on average, a 75 watt GSL lamp leading to a change in load of 57 watts. Average hours of use are assumed to be 2.5 hours per day or 912 hours per year. For fluorescent tubes, it is assumed that a 36 watt T8 tube replaces, on average, a 40 watt T12 tube leading to a change in load of 57 watts. Average hours of use are assumed to be 8 hours per day or 2,920 hours per year. For sodium vapor lamps, it is assumed that a 70 watt sodium vapor lamp replaces, on average, a 125 watt mercury vapor lamp leading to a change of 55 watts. Average hours of use are assumed to be 11 hours per day or 4,015 hours per year.

The unit energy savings results are shown below. Estimated savings per unit are $52.0 \mathrm{kWh}$ for a CFL replacing an incandescent lamp, $11.7 \mathrm{kWh}$ per year for a T5 to T8 lamp replacing a T12 lamp and $220.8 \mathrm{kWh}$ per year for a sodium vapor lamp replacing a mercury vapor lamp. These results are the estimated savings that would be experienced at the customers' meters. At the system level, savings would be about ten percent higher to allow for transmission losses and distribution losses.

Energy savings were calculated for each product in each country as the product of units savings multiplied by ELI sales impacts for the relevant product type. Savings for each country were then calculated as the sum of savings for each product in that country. In preparing greenhouse gas inventories, we use algorithms that estimate emissions as the product of emission factors multiplied by fuel consumption multiplied by the appropriate oxidization fraction.

Table 6: Customer savings at the meter.

\begin{tabular}{|l|l|l|l|l|l|}
\hline & $\begin{array}{l}\text { Base } \\
\text { lamp } \\
(\mathrm{W})\end{array}$ & $\begin{array}{l}\text { Efficient } \\
\text { lamp } \\
(\mathrm{W})\end{array}$ & $\begin{array}{l}\text { Unit } \\
\text { savings } \\
(\mathrm{W})\end{array}$ & $\begin{array}{l}\text { Hours of use } \\
\text { (per year) }\end{array}$ & $\begin{array}{l}\text { Unit } \\
\text { savings } \\
(\mathrm{kWh})\end{array}$ \\
\hline $\begin{array}{l}\text { CFL } \\
\text { v GLS }\end{array}$ & 75 & 18 & 57 & 912 & 52.0 \\
\hline $\begin{array}{l}\text { T8 } \\
\text { v T12 }\end{array}$ & 40 & 36 & 4 & 2,920 & 11.7 \\
\hline $\begin{array}{l}\text { Sodium } \\
\text { v Mercury }\end{array}$ & 125 & 70 & 55 & 4,015 & 220.8 \\
\hline
\end{tabular}

The Intergovernmental Panel on Climate Change [10-12] has suggested three main approaches to the analysis of greenhouse gas emissions as follows. Tier 1 emission factors represent average emissions per unit of fuel consumed and are not technology specific. Like the other IPCC emission factors, the Tier 1 factors are expressed in terms of quantity of emissions per terajoule of energy, so that fuel data in mass or volumetric terms must be converted to their energy equivalents before the emission factors can be applied. Tier 2 emission factors 
provide a more detailed approach by disaggregating fuel consumption data using types of technologies that are homogenous enough to realistically permit the use of representative emission factors. Tier 3 emission factors are site and plant specific emission factors and require considerable detailed information.

This study uses essentially a Tier 1 analysis, with estimated country-specific emissions factors as shown in Table 7. Energy savings are $848 \mathrm{GWh}$ per year, while carbon dioxide savings are 484 kilotonnes, sulphur dioxide savings are 4,220 tonnes and nitrous oxide savings are 2,006 tonnes.

Table 7: Annual energy savings and emissions reductions.

\begin{tabular}{|l|l|l|l|l|l|l|l|}
\hline & $\begin{array}{l}\text { Energy } \\
\text { savings } \\
(\mathrm{GWh})\end{array}$ & $\begin{array}{l}\mathrm{CO}_{2} \text { per } \\
\mathrm{kWh} \\
(\mathrm{kgms})\end{array}$ & $\begin{array}{l}\mathrm{SO}_{2} \text { per } \\
\mathrm{kWh} \\
(\mathrm{gms})\end{array}$ & $\begin{array}{l}\mathrm{NO}_{\mathrm{x}} \text { per } \\
\mathrm{kWh} \\
(\mathrm{gms})\end{array}$ & $\begin{array}{l}\mathrm{CO}_{2} \\
\text { total } \\
(\mathrm{ktonne})\end{array}$ & $\begin{array}{l}\mathrm{SO}_{2} \\
\text { total } \\
\text { (tonne) }\end{array}$ & $\begin{array}{l}\mathrm{NO}_{\mathrm{x}} \\
\text { total } \\
\text { tonne) }\end{array}$ \\
\hline Argentina & 103.7 & 0.27 & 2.46 & 1.12 & 28.0 & 255.5 & 116.1 \\
\hline Peru & 370.1 & 0.36 & 3.28 & 1.49 & 133.2 & $1,017.7$ & 551.4 \\
\hline Philippines & 147.8 & 0.39 & 3.56 & 1.61 & 57.6 & 526.2 & 238.0 \\
\hline S Africa & 226.9 & 1.17 & 10.67 & 4.84 & 265.5 & $2,421.0$ & $1,098.2$ \\
\hline Total & 848.5 & - & - & - & 484.3 & $4,220.4$ & $2,006.4$ \\
\hline
\end{tabular}

\section{Conclusions}

The purpose of this paper is to summarize a market evaluation of the ELI programs in Argentina, Peru, the Philippines and South Africa. At the time of launch of ELI, average lighting efficiency levels in Argentina, Peru, the Philippines and South Africa were well below those achievable with currently available cost-effective technologies. To address the constraints on improved lighting efficiency, the four developing country ELI programs included a wide range of activities including advertising and promotions, product testing and labelling, school programs, technology development, and subsidy and directinstall demonstration projects.

The four developing countries ELI programs had a number of major impacts, including the following. First, sales of compact fluorescent lamps increased by 1,926,000 units in Argentina, 5,766,000 units in Peru, 2,762,000 units in the Philippines and 3,780,000 units per year in South Africa. Second, sales of T5-T8 lamps increased by 302,000 units in Argentina, 418,000 units in Peru, 354,000 units in the Philippines and 2,594,000 units in South Africa. Third, sales of sodium vapor lamp sales increased by 296,000 units in Peru, but the data was not adequate to allow modeling of high intensity discharge lighting sales in the other ELI countries. Fourth, energy savings were some $849 \mathrm{GWh}$ per year. Fifth, carbon dioxide emissions savings were about 484 kilotonnes per year; sulphur dioxide emissions savings were about 4,220 tonnes per year; and nitrous oxides emissions savings were about 2,004 tonnes per year.

\section{Acknowledgements}

Special thanks are due to Joe Lopes and the members of the ELI evaluation team and to Russell Sturm of the IFC. 


\section{References}

[1] United Nations Environmental Programme, Global Environmental Outlook GEO-4, Malta: Progress Press Ltd, 2007.

[2] World Health Organization, WHO Air Quality Guidelines for Particulate Matter, Ozone, Nitrogen Dioxide and Sulphur Dioxide, Global Update 2005, Geneva: World Health Organization, 2005.

[3] United Nations Framework Convention on Climate Change. New York: United Nations Conference on Environment and Development, 1997.

[4] Hobbs, B. F., H. B. Rouse and D. T. Hoog. "Measuring the Economic Value of Demand-Side and Supply Resources in Integrated Resource Planning Models," IEEE Transactions on Power Systems, Vol. 8, No. 3, 1993, pp. 979-985.

[5] Duke, R. and Kammen, D., "Economic Indicators of Market Transformation Programs," The Energy Journal, Vol. 20, No. 4, 1999.

[6] Horowitz, M., "Economic Indicators of Market Transformation: Energy Efficient Lighting and EPA's Green Lights," The Energy Journal, Vol. 22, No. 4, 2001.

[7] Horowitz, M. and Haeri, H., "Energy Economic Efficiency versus Energy Efficiency: Do Model Conservation Standards Make Good Sense?” Energy Economics, Vol. 12, No. 2, 1990.

[8] Jaffe, A. and Stavins, R.: "Dynamic Incentives of Environmental Regulations: The Impact of Alternative Policy Instruments on Technology Diffusion," Journal of Environmental Economics and Environment, Vol. 29, 1995.

[9] World Bank. Unpublished power generation fuel consumption data for ELI countries.

[10] Intergovernmental Panel on Climate Change, Climate Change 2001: Synthesis Report, Cambridge: Cambridge University Press, 2001.

[11] Intergovernmental Panel on Climate Change, Climate Change 2001: The Scientific Basis, Cambridge: Cambridge University Press, 2001.

[12] Intergovernmental Panel on Climate Change, Climate Change 2001: Impacts, Adaptation and Vulnerability, Cambridge: Cambridge University Press, 2001. 